\title{
Method Development and Total Uncertainty Estimation for Boron, Sulfur and Phosphorus Determination in Mineral Fertilizer Using ICP OES
}

\author{
Tiago C. de Oliveira, ${ }^{a}$ Roger T. Rampazzo, ${ }^{a}$ Marco F. Ferrão ${ }^{b}$ and Dirce Pozebon*,b \\ ${ }^{a}$ Laboratório Nacional Agropecuário do Rio Grande do Sul, Ministério da Agricultura Pecuária e \\ Abastecimento, Estrada da Ponta Grossa 3036, 91780-580 Porto Alegre-RS, Brazil \\ ${ }^{b}$ Instituto de Química, Universidade Federal do Rio Grande do Sul, \\ 91501-970 Porto Alegre-RS, Brazil
}

\begin{abstract}
This study deals with $\mathrm{B}, \mathrm{S}$, and $\mathrm{P}$ determination in mineral fertilizer and $\mathrm{S}$ in commercial sulfur-formulation using inductively coupled plasma optical emission spectrometry. According to multivariate optimization using a Doehlert matrix, the analytes extraction in fertlizer can be conducted in open flask and heating on hot plate or in closed flask in microwave oven. However, when $\mathrm{S}$ is present in its elemental form in the fertilizer, the sample must be decomposed in closed flask in microwave oven for accurate $S$ quantification. The uncertainties of the method were estimated according to the bottom-up approach, which were 7.1, 4.3, and 7.8\% for B, S and P, respectively. The main sources of uncertainty identified were the intermediate precision, accuracy, regression of the calibration curve and errors originated from volumetric flasks and pipettes. Satisfactory results were obtained in the analysis of certified reference materials and sample from inter-laboratory programs as well as $\mathrm{S}$ recovery in a commercial elemental sulfur sample.
\end{abstract}

Keywords: mineral fertilizer, ICP OES, determination of B, S and P, uncertainty, multivariate optimization

\section{Introduction}

Mineral fertilizer is the seventh most imported product in Brazil, corresponding to $3.7 \%$ of imports in 2014, or about 8.5 billion dollars. ${ }^{1}$ This corresponds to about 32 billion $\mathrm{kg}$ of fertilizers, almost twice the amount of fertilizer produced in Brazil in the same year. ${ }^{2}$ The Food and Agriculture Organization of the United Nations (FAO) estimated in 187 billion $\mathrm{kg}$ the amount of fertilizer consumed worldwide in 2014, predicting a consumption of 197 billion $\mathrm{kg}$ in $2016 .^{3}$ The International Fertilizer Industry Association estimates the need of approximately 200 billion $\mathrm{kg}$ of fertilizer in $2018 .{ }^{4}$

The large amount of fertilizer consumed gives rise to fraud, alteration and forgery of the commercialized product, with nutrient concentration lower than that declared by the suppliers. The current Brazilian legislation predicts such swindles and classifies them as mild, serious or very serious, depending on the difference among the declared nutrient concentration and the actual one. ${ }^{5}$

\footnotetext{
*e-mail: dircepoz@iq.ufrgs.br
}

Most official methods applied to the control of nutrient elements in fertilizers in Brazil are volumetric and gravimetric (classical methods of analysis). ${ }^{6-11}$ There is deficiency of instrumental methods and regulatory proposals for employment of techniques with multi-element feature such as inductively coupled plasma optical emission spectrometry (ICP OES). The Brazilian National Standards Organization (Associação Brasileira de Normas Técnicas, ABNT) has not published any standard on this subject yet. ${ }^{12}$ However, in 2006 the Association of Analytical Communities (AOAC) International proposed an official method of analysis (OMA) for determination of As, Cd, $\mathrm{Co}, \mathrm{Cr}, \mathrm{Pb}, \mathrm{Mo}, \mathrm{Ni}$ and Se by ICP OES..$^{13}$ The AOAC International has also proposed the determination of $\mathrm{B},{ }^{14}$ $\mathrm{P}^{15}$ and $\mathrm{S}^{16}$ by means of ICP OES. However, these proposals are not yet official methods (at least in Brazil) and the use of ICP OES is still being discussed by AOAC. ${ }^{17}$

The ICP OES technique has been applied to the determination of $\mathrm{B}, \mathrm{P}$, and $\mathrm{S}$ in various other matrices, ${ }^{18}$ but little application for mineral fertilizer has been reported. Souza et al. ${ }^{19}$ developed a method for simultaneous determination of nutrient elements in fertilizers by ICP OES. The authors considered the results as promising and 
suitable to the Brazilian legislation. However, such method has still not been validated and implemented.

An additional difficulty found in mineral fertilizer analysis using classical methods is the determination of $\mathrm{S}$ when present in its elemental form. In this case, it is necessary to convert $\mathrm{S}$ to $\mathrm{SO}_{4}{ }^{2-}$ that is then gravimetrically quantified. ${ }^{6}$ Thus, the advantages of using an instrumental technique such as ICP OES is clear, in virtue of the highest sample throughput, simplicity and sensitivity. Although there is the possibility of interferences caused by the mineral fertilizer matrix, it can be overcome by appropriate dilution of the sample solution and/or matrix matching calibration, in addition to adjustments of instrumental parameters that can be carried out following multivariate approaches. ${ }^{20}$ In this sense, Doehlert matrices ${ }^{21}$ have been used for optimization of sample preparation methods $\mathrm{s}^{22-24}$ and instrumental parameterts ${ }^{19,25}$ for subsequent element determination by means of ICP OES.

Considering the importance of fertilizer for the worldwide economy, possibility of frauds and demands for faster and practical methods that can be employed by regulatory agencies, the purpose of the present study is to develop methods for determination of $\mathrm{B}, \mathrm{S}$ and $\mathrm{P}$ in mineral fertilizers by ICP OES, to validate the methods and estimate the uncertainty.

\section{Experimental}

Instruments

A Vista-MPX (Varian/Agilent Technologies, Santa Clara, CA, USA) spectrometer was employed for B, P and $S$ determination. Such instrument is set for radial view of the ICP. Solutions were introduced into the ICP through a V-groove nebulizer fitted on a Sturman-Masters spray chamber, both supplied by the ICP OES manufacturer. A standard quartz torch adapted to a quartz injector tube (1.4 mm of internal diameter) was used. Argon of analytical grade (purity of $99.999 \%$ ), supplied by White Martins/ Praxair (Sapucaia do Sul, RS, Brazil), was used as plasma, nebulizer, auxiliary and purging gas of the optical system.

The most sensitive spectral lines considered free of spectral interference by major elements in mineral fertilizers were monitored. ${ }^{26}$ These spectral lines are suggested by the software accompanying the ICP OES instrument employed. Table 1 summarizes the instrumental parameters (after optimization or recommended by the manufacturer of the ICP OES instrument) and spectral lines monitored, for determinations using ICP OES.

Sample decomposition assisted by microwave radiation was carried out in a Multiwave 3000/Anton Paar microwave
Table 1. Instrumental parameters, spectral lines and conditions used for ICP OES

\begin{tabular}{lc}
\hline Parameter & Condition \\
\hline Plasma power / W & $1450^{\mathrm{a}}(750-1450)$ \\
Plasma gas flow rate / $\left(\mathrm{L} \mathrm{min}^{-1}\right)$ & 15 \\
Auxiliary gas flow rate / $\left(\mathrm{L} \mathrm{min}^{-1}\right)$ & 2.25 \\
Purge gas flow rate / $\left(\mathrm{L} \mathrm{min}^{-1}\right)$ & 3 \\
Nebulizer gas pressure / $\mathrm{kPa}$ & $180,{ }^{\mathrm{a}} 200,220$ \\
Peristaltic pump speed / rpm & $24^{\mathrm{a}}\left(2.4 \mathrm{~mL} \mathrm{~min}^{-1}\right) ; 6-24$ \\
Observation height / mm & 10 \\
Replicates per reading & 3 \\
Spectral line / nm & $\mathrm{B}(\mathrm{I}) 249.772, \mathrm{Mg}(\mathrm{I}) 285.213$, \\
& $\mathrm{Mg}(\mathrm{II}) 280.270, \mathrm{~S}(\mathrm{I}) 181.972$, \\
& $\mathrm{P}(\mathrm{I}) 214.914, \mathrm{P}(\mathrm{I}) 213.618, \mathrm{P}(\mathrm{I})$ \\
& $213.547^{\mathrm{b}}$
\end{tabular}

a Selected after optimization or method development; ${ }^{\mathrm{b}}$ spectral line selected; (I): atomic; (II): ionic.

(Graz, Austria) oven equipped with $80 \mathrm{~mL}$ quartz flasks. A hot plate (Quimis, Diadema, SP, Brazil) with a maximum power of $2000 \mathrm{~W}$ and temperature of $300^{\circ} \mathrm{C}$ was employed as heating source for analytes extraction in open flask.

The samples were weighed in a XS204 Mettler Toledo (Columbus, OH, USA) balance, with precision of $0.1 \mathrm{mg}$. This balance was calibrated by the Brazilian Calibration Network (Rede Brasileira de Calibração (RBC)), meeting the calibration criteria (maximum error of $0.3 \mathrm{mg}$ ). All volumetric flasks and pipettes used throughout the study were also calibrated by RBC. The maximum error tolerated for the volumetric flasks and pipettes used are presented in Table S1 (Supplementary Information).

Phosphorus extraction by neutral ammonium citrate (NAC) was conducted in a mechanical stirring oven (MA 022, Marconi, Piracicaba, SP, Brazil), maintained at 65 to $75^{\circ} \mathrm{C}$ during the extraction. The temperature was monitored by means of a thermometer calibrated by RBC.

All measurements were performed at room temperature, controlled and maintained at 15 to $25^{\circ} \mathrm{C}$. The temperature was measured by means of thermometer calibrated by RBC $\left(2{ }^{\circ} \mathrm{C}\right.$ is the maximum error permissible). The water used for samples and solutions preparation was purified (to achieve $18.18 \mathrm{M} \Omega \mathrm{cm}$ resistivity) in a Master All/Gehaka system (São Paulo, SP, Brazil).

\section{Reagents, solutions and materials}

The calibration solutions were prepared in $1 \%(\mathrm{v} / \mathrm{v})$ $\mathrm{HNO}_{3}$, by serial dilution of the following certified reference solutions: (i) boric acid in water, $1000 \pm 4 \mu \mathrm{gL}^{-1} \mathrm{~B}$ (Fluka Analytical, St. Louis, Mo, USA); (ii) ammonium sulfate in water, $1004 \pm 5 \mathrm{mg} \mathrm{L}^{-1} \mathrm{~S}$ (SCP Science, Quebec, Canada); and (iii) ammonium dihydrogen phosphate in water, 
$1001 \pm 4 \mu \mathrm{g} \mathrm{mL} \mathrm{m}^{-1} \mathrm{P}$ (SCP Science). The concentration of the calibration solutions were as follows; B: 0.03, 0.12, $0.21,0.30,0.39$ and $0.48 \mathrm{mg} \mathrm{L}^{-1}$; $\mathrm{P}$ and $\mathrm{S}: 3,12,21,30,39$ and $48 \mathrm{mg} \mathrm{L}^{-1}$. The calibration solutions were prepared in triplicate. For each analyte, the sample solution was diluted so that the analyte concentration in the final solution was as close as possible to the central point of the calibration curve and at least twice the concentration correspondent to the lowest point.

In order to evaluate matrix effects, the following test solutions (all in $2 \% \mathrm{HNO}_{3}(\mathrm{v} / \mathrm{v})$ ) were prepared: (i) $\mathrm{K}$, corresponding to $120 \mathrm{mg} \mathrm{L}^{-1} \mathrm{~K}_{2} \mathrm{O}$, from $\mathrm{KCl}$ (purity of 99.0 to $100.5 \%$, Spectrum Química e Diagnóstica, Campo Grande, MS, Brazil); (ii) $30 \mathrm{mg} \mathrm{L}^{-1} \mathrm{Ca}$, from $1000 \pm 4 \mathrm{mg} \mathrm{L}^{-1} \mathrm{Ca}$ solution; (iii) $30 \mathrm{mg} \mathrm{L}^{-1} \mathrm{Mg}$, from $1001 \pm 6 \mathrm{mg} \mathrm{L}^{-1} \mathrm{Mg}$ solution; (iv) $30 \mathrm{mg} \mathrm{L}^{-1} \mathrm{Cu}$, from $1001 \pm 4 \mathrm{mg} \mathrm{L}^{-1} \mathrm{Cu}$ solution; (v) $30 \mathrm{mg} \mathrm{mL}^{-1} \mathrm{Zn}$, from $1001 \pm 4 \mathrm{mg} \mathrm{L}^{-1} \mathrm{Zn}$ solution; and (vi) $30 \mathrm{mg} \mathrm{L}^{-1} \mathrm{Mn}$, from $998 \pm 4 \mathrm{mg} \mathrm{L}^{-1} \mathrm{Mn}$ solution. The stock solutions of $\mathrm{Ca}, \mathrm{Mg}, \mathrm{Cu}, \mathrm{Zn}$, and $\mathrm{Mn}$ were purchased from Fluka. An NAC solution was prepared according to the official methodology, ${ }^{6}$ which is detailed in Supplementary Information. Citric acid (solid) (at least $99.5 \%$ pure, from Vetec, Duque de Caxias, RJ, Brazil) and $28 \% \mathrm{~m} / \mathrm{m} \mathrm{NH}_{4} \mathrm{OH}$ (Cromato Produtos Químicos, Diadema, SP, Brazil) were used to prepare the NAC solution.

Nitric acid $(67-69 \% \mathrm{~m} / \mathrm{m})$, used for samples and solution preparation, was purchased from Carlo Erba (Rodano, Italy). The maximum concentrations of B, S, and $\mathrm{P}$ in this acid were 1.0, 0.3 and $0.01 \mu \mathrm{g} \mathrm{L}^{-1}$, respectively. Analytical grade $\mathrm{HCl}$ (Vetec) purified in the laboratory by sub-boiling distillation (in a Subpur distiller from Milestone, Sorisole, Italy) was used.

\section{Samples and sample preparation}

A sample of elemental sulfur (purity of 99.5 to $100.5 \%$ ) was purchased from Delaware, Porto Alegre, RS, Brazil. The certified reference materials National Institute of Standards and Technology (NIST) 694 (western phosphate rock) and NIST 695 (trace elements in multi-nutrient fertilizer) were analyzed for evaluation of the accuracy of the method for determination of total S, P and B in fertilizer. Fertilizer samples that had been analyzed in proficiency testing programs carried out by the Brazilian Ministry of Agriculture, Livestock and Supply (Ministério da Agricultura, Pecuária e Abastecimento (MAPA)) were utilized for method development ${ }^{27}$ as well as samples collected and analyzed by MAPA in legal actions.

The following optimized procedure was conducted for samples decomposition assisted by microwave radiation:
$250 \mathrm{mg}$ of sample were weighed and quantitatively transferred to the quartz flask accompanying the microwave oven. Subsequently, $5 \mathrm{~mL}$ of water and $3 \mathrm{~mL}$ of $\mathrm{HNO}_{3}$ were added to the sample in the flask that was then closed, placed in the rotor and transferred to the microwave oven. The microwave oven program that was run consisted of (i) $600 \mathrm{~W}$, ramp and plateau of $5 \mathrm{~min}$; and (ii) $1200 \mathrm{~W}$, ramp of $5 \mathrm{~min}$ and plateau of $20 \mathrm{~min}$. After cooling to room temperature, the obtained solution was quantitatively transferred to a $200 \mathrm{~mL}$ volumetric flask, being filtered through quantitative paper (porosity of $250 \mu \mathrm{m}$ ) and washed with water until completing the flask volume. When $\mathrm{P}$ was extracted using NAC the official method ${ }^{6}$ was followed, which is detailed in Supplementary Information.

\section{Multivariate analysis and computational tools}

The analytes extraction and the instrumental parameters were optimized following a multivariate approach - a Doehlert matrix was used. The Doehlert 1.0 program developed by Teófilo and Ferreira ${ }^{28}$ at the Instituto de Química of Universidade Estadual de Campinas (Campinas, SP, Brazil) was applied. This program is available online..$^{29}$ All equations and response surfaces were obtained through the spreadsheet "Planejamento Doehlert modelo quadrático com 3 variáveis" of PDQ3var software.

The worksheet FOR UGQ 085 Rev01 "Planilha para verificação da linearidade", formulated and validated by Laboratório Nacional Agropecuário (LANAGRO, Goiânia, GO, Brazil), available for internal use at LANAGRO network, was employed for the linearity evaluation. The application of this worksheet was published by Souza and Junqueira. ${ }^{30}$ This worksheet allows evaluating the presence of outliers, normality, independence of residues, cedasticity and linearity deviations.

Except otherwise cited, all data obtained throughout the study were processed using Microsoft Excel (Windows 2010).

The standard uncertainty of the methods was estimated according to equation 1, following the International Organization for Standardization (ISO) Guide to the Expression of Uncertainty in Measurement (GUM). ${ }^{31}$

$$
\mathrm{u}=\mathrm{k}\left(\mathrm{V}_{\mathrm{eff}}\right) \times \sqrt{\left(\begin{array}{l}
\left(\frac{\mathrm{u}_{\mathrm{COV}} \times \mathrm{DF}}{10000 \times \mathrm{m}}\right)^{2}+\left(\mathrm{u}_{\mathrm{CP}} \times \frac{\frac{\mathrm{DF}}{\mathrm{PC}}}{10000 \times \mathrm{m}}\right)^{2}+\left(\mathrm{u}_{\mathrm{PC} \times} \times \frac{-\frac{\mathrm{CP}}{\mathrm{PC}^{2}} \times \mathrm{DF}}{10000 \times \mathrm{m}}\right)^{2}+ \\
\sum\left(\frac{\mathrm{u}_{\mathrm{Di}} \times \mathrm{S}}{10000 \times \mathrm{m}}\right)^{2}+\sum\left(\frac{\mathrm{u}_{\mathrm{ETi}} \times \mathrm{S}}{10000 \times \mathrm{m}}\right)^{2}+\left(\mathrm{u}_{\mathrm{ETB}} \times-\frac{\mathrm{S} \times \mathrm{DF}}{10000 \mathrm{~m}^{2}}\right)^{2}+ \\
\left(-\frac{\mathrm{u}_{\mathrm{XB}} \times \mathrm{S} \times \mathrm{DF}}{\mathrm{m}^{2}}\right)^{2}+\left(-\frac{\mathrm{u}_{\mathrm{RB}} \times \mathrm{S} \times \mathrm{DF}}{\mathrm{m}^{2}}\right)^{2}+\left(\mathrm{u}_{\mathrm{RER}}\right)^{2}
\end{array}\right.}
$$

where S: analyte concentration in the sample solution; DF: dilution factor of sample solution; m: sample mass; 
$\mathrm{k}\left(\mathrm{V}_{\text {eff }}\right)$ : coverage factor; $\mathrm{u}_{\mathrm{cov}}$ : standard uncertainty of the regression of calibration curve; $\mathrm{u}_{\mathrm{CP}}$ : standard uncertainty of the standard concentration; PC: dilution of the calibration solution corresponding to the highest concentration in the calibration curve; $\mathrm{u}_{\mathrm{PC}}$ : standard uncertainty of the dilution of the calibration solution corresponding to the highest concentration in the calibration curve; CP: standard concentration used for calibration solutions; $\mathrm{u}_{\mathrm{Di}}$ : standard uncertainty of volumetric flasks and pipettes used for sample dilution; $\mathrm{u}_{\mathrm{ETI}}$ : standard uncertainty of liquid expansion; $\mathrm{u}_{\mathrm{Eтв}}$ : standard uncertainty of balance error; $\mathrm{u}_{\mathrm{XB}}$ : standard uncertainty of balance eccentricity; $\mathrm{u}_{\mathrm{RB}}$ : standard uncertainty of balance resolution; and $\mathrm{u}_{\mathrm{R} \& \mathrm{R}}$ : standard uncertainty of intermediate precision.

\section{Results and Discussion}

\section{Optimization of sample extraction/decomposition}

A Doehlert matrix with three variables, ${ }^{28}$ represented as a cube-octahedron, ${ }^{32}$ was used for multivariate optimization. The composition of the experimental array, with the definition of values used for each experiment, can be seen in Figure S1 and Table S2 (Supplementary Information).
A fertilizer sample (named sample A) containing 0.248, 9.98 and $7.18 \%(\mathrm{~m} / \mathrm{m})$ of B, S and P (extracted with NAC), respectively, was used for multivariate optimization of the sample preparation procedure. For $\mathrm{S}$, a commercial sample of elemental S (named sample B) was used. The volume of $\mathrm{HNO}_{3}$ and $\mathrm{HCl}$ added to the sample and the time of extraction were evaluated, as detailed in Table 2. The microwave power applied was fixed at $1200 \mathrm{~W}$. This variable could not be included because it changes automatically in order to maintain the pressure inside the flask.

For $\mathrm{S}$ extraction in sample $\mathrm{A}$, the $\mathrm{HNO}_{3}$ concentration was considered significant and inversely proportional (the negative standardized effect was 3.15). However, the maximum concentration of $\mathrm{S}$ was found for the minimum time (20 min) and $3 \mathrm{~mL}$ of $\mathrm{HNO}_{3}$. For $\mathrm{S}$ extraction in sample $\mathrm{B}$, all factors were considered significant. The volume of $\mathrm{HNO}_{3}$ added revealed a proportional standardized effect (122.23) while the effect for the $\mathrm{HCl}$ amount revealed to be the opposite $(-13.81)$. The time of extraction also had a proportional standardized effect (7.08). On the other hand, no effect was significant for B and P. The coefficient of determination $\left(\mathrm{R}^{2}\right)$ in Table 2 demonstrates the quality of the linear regression; the closer to the unity, the more significant are the effects studied.

Table 2. Factors and levels evaluated in multivariate optimization of the analytes extraction in microwave oven and obtained results

\begin{tabular}{|c|c|c|c|c|c|c|c|}
\hline \multirow{3}{*}{ Experiment } & \multirow{2}{*}{\multicolumn{3}{|c|}{ Levels and factors }} & \multicolumn{4}{|c|}{ Concentrations found / \% $(\mathrm{m} / \mathrm{m})$} \\
\hline & & & & \multicolumn{3}{|c|}{ Sample A } & \multirow{2}{*}{$\begin{array}{c}\text { Sample B } \\
\mathrm{S} \\
\end{array}$} \\
\hline & $\mathrm{HNO}_{3} / \mathrm{mL}$ & $\mathrm{HCl} / \mathrm{mL}$ & time / min & $\mathrm{S}$ & $\mathrm{P}$ & $\mathrm{B}$ & \\
\hline 1 & 4.00 & 2.00 & 40 & 9.44 & 7.17 & 0.2537 & 99.35 \\
\hline 2 & 3.00 & 3.73 & 40 & 9.92 & 7.38 & 0.2573 & 100.5 \\
\hline 3 & 3.00 & 2.58 & 60 & 10.35 & 7.33 & 0.2556 & 99.31 \\
\hline 4 & 0.00 & 2.00 & 40 & 9.98 & 7.98 & 0.2570 & 3.35 \\
\hline 5 & 1.00 & 0.27 & 40 & 10.78 & 7.06 & 0.2487 & 94.46 \\
\hline 6 & 1.00 & 1.42 & 20 & 10.45 & 7.59 & 0.2552 & 63.26 \\
\hline 7 & 3.00 & 0.27 & 40 & 10.11 & 7.20 & 0.2526 & 99.42 \\
\hline 8 & 3.00 & 1.42 & 20 & 10.99 & 7.04 & 0.2474 & 102.1 \\
\hline 9 & 1.00 & 3.73 & 40 & 10.88 & 7.23 & 0.2483 & 70.92 \\
\hline 10 & 2.00 & 3.15 & 20 & 10.46 & 7.58 & 0.2602 & 102.0 \\
\hline 11 & 1.00 & 2.58 & 60 & 10.70 & 7.08 & 0.2452 & 76.54 \\
\hline 12 & 2.00 & 0.85 & 60 & 10.59 & 7.68 & 0.2614 & 101.7 \\
\hline 13 & 2.00 & 2.00 & 40 & 10.31 & 7.30 & 0.2575 & 99.01 \\
\hline 14 & 2.00 & 2.00 & 40 & 10.03 & 7.30 & 0.2559 & 99.81 \\
\hline 15 & 2.00 & 2.00 & 40 & 10.06 & 7.35 & 0.2520 & 99.11 \\
\hline 16 & 2.00 & 2.00 & 40 & 10.46 & 8.07 & 0.2573 & 98.81 \\
\hline 17 & 2.00 & 2.00 & 40 & 10.47 & 7.89 & 0.2578 & 99.94 \\
\hline 18 & 2.00 & 2.00 & 40 & 10.01 & 7.44 & 0.2630 & 100.3 \\
\hline $\mathrm{R}^{2}$ & - & - & - & 0.7357 & 0.5164 & 0.7339 & 0.9271 \\
\hline
\end{tabular}

$\mathrm{R}^{2}$ : coefficient of determination. 
Figure 1 shows the normal probability plot and the response surface for the extraction of elemental sulfur. Considering that the effect of the $\mathrm{HCl}$ amount is inversely proportional, the volume of this acid was fixed in $0.27 \mathrm{~mL}$ (the lowest volume tested, see Table 2).

Despite the importance of time on $\mathrm{S}$ extraction, different conclusions can be drawn if Figures $1 \mathrm{a}$ and $1 \mathrm{~b}$ are analyzed independently. Figure 1a indicates that time is significant when less $\mathrm{HNO}_{3}$ is added. However, when the volume of $\mathrm{HNO}_{3}$ is set at $3 \mathrm{~mL}$ (about 0.5 for $\mathrm{X}_{1}$ in Table S2) the variation of this factor becomes negligible. This highlights the importance of multivariate optimization. According to the results obtained, the time of extraction and the volume of $\mathrm{HCl}$ can be reduced to the minimum values investigated. Thus, $3 \mathrm{~mL}$ of $\mathrm{HNO}_{3}$ and $20 \mathrm{~min}$ were selected, without addition of $\mathrm{HCl}$. These conditions were also considered optimal for extraction of all analytes in sample A, based on the significance of the effects cited above.

Considering that the nutrient elements in mineral fertilizers can be more cheaply, quickly and easily extracted in open flask and heating on hot plate than in closed flask and heating in microwave oven, the first procedure was also investigated. To this end, the same Doehlert matrix illustrated in Figure S1 was applied. The factors evaluated were time of extraction (3 levels), volume of $\mathrm{HNO}_{3}$ (5 levels) and $\mathrm{HCl}$ (7 levels). The volume of the extraction solution was always elevated to $8 \mathrm{~mL}$ by adding water. The time started to be counted only after the mixture began to boil. The results obtained in the second experiment of multivariate optimization demonstrated that none of the studied factors had significant influence on $\mathrm{S}$ and $\mathrm{B}$ extraction. However, the amount of $\mathrm{HNO}_{3}$ influenced $\mathrm{P}$ extraction (standardized effect of -3.94 ), showing that the $\mathrm{P}$ concentration found was lower when more than $1 \mathrm{~mL}$ of $\mathrm{HNO}_{3}$ was added.

Based on the results obtained in the second study of multivariate optimization, it was concluded that the extraction of S, B and P in fertilizer can be conducted in

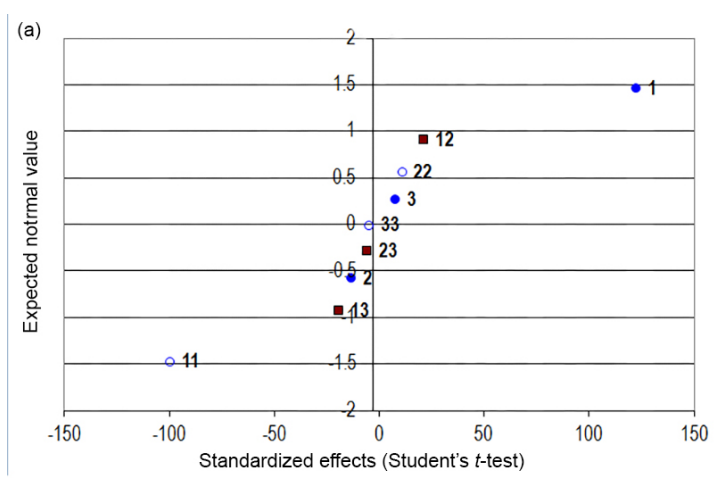

open flask and heating on hot plate. In this case, $1 \mathrm{~mL}$ of $\mathrm{HCl}+1 \mathrm{~mL} \mathrm{HNO}_{3}+6 \mathrm{~mL}$ of water should be added to $250 \mathrm{mg}$ of sample, maintaining the mixture under boiling for $2 \mathrm{~min}$.

Thus, sample digestion in microwave oven or the analyte extraction in open flask and heating on hot plate can be employed when the determination of total $\mathrm{S}$, $\mathrm{P}$, and $\mathrm{B}$ in fertilizer is intended. However, when $\mathrm{S}$ is present in its elemental form in the analyzed fertilizer, sample decomposition in microwave oven is mandatory. Nevertheless, the official method ${ }^{6}$ establishes that $\mathrm{P}$ in fertilizer must be extracted using NAC. Therefore, to validate the method and calculate the standard uncertainty, the fertilizer sample was decomposed in microwave oven for the determination of $\mathrm{B}$ and $\mathrm{S}$, while $\mathrm{P}$ was separately extracted with NAC, following the official method in this case (Supplementary Information). This also allowed comparing the $\mathrm{P}$ concentration found with that reported for samples from proficiency tests. The exception was the certified fertilizers where $\mathrm{P}$ was also quantified in the solution of the digested sample, for adequate comparison with the certified value.

\section{Optimization of ICP OES operation}

The Doehlert matrix illustrated in Figure S1 was also applied for optimizing the ICP OES operation. The experiments were conducted randomly and the criterion of selection was the sensitivity. The solutions used were those obtained from sample A decomposed in microwave oven (the same sample solution used in the experiments conducted for optimization of analyte extraction/sample decomposition). The pressure of the nebulizer gas, plasma power, and the peristaltic pump speed were evaluated.

The nebulizer gas pressure influences the nebulizer gas flow rate while the peristaltic pump speed determines the sample uptake rate and both influence the formation and transport of the aerosol to the ICP. ${ }^{33}$ They also remarkably

(b)

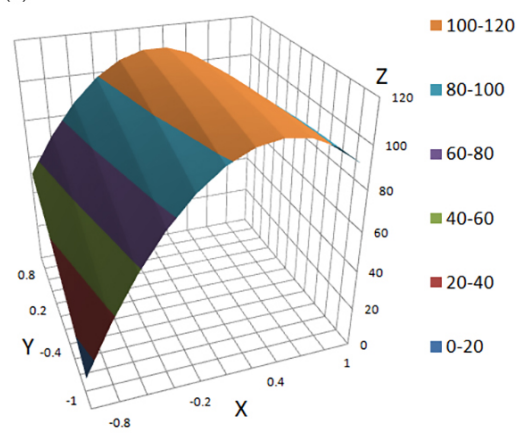

Figure 1. Influence of $\mathrm{HNO}_{3}$ and time on the extraction of elemental sulfur assisted by microwave radiation; (a): normal probability; (b) surface response. In (b) the $\mathrm{x}$-axis corresponds to the volume of $\mathrm{HNO}_{3}$ added (in steps), $\mathrm{y}$-axis to the time of extraction (in steps) and z-axis to the $\mathrm{S}$ concentration in \% (m/m). 
influence the plasma robustness. ${ }^{34}$ The ratio $\mathrm{Mg}^{\mathrm{II}}$ $280.270 \mathrm{~nm} / \mathrm{Mg}^{\mathrm{I}} 285.213 \mathrm{~nm}$ was also measured in order to evaluate the plasma robustness, as suggested by other researchers. ${ }^{35,36}$ Monitoring the ratio $\mathrm{Mg} / \mathrm{Mg}^{\mathrm{II}}$ is based on the principle that ionic states are more sensitive to changes of plasma parameters than atomic states. Thus, a high ratio of $\mathrm{Mg}^{\mathrm{II}} / \mathrm{Mg}^{\mathrm{I}}$ denotes less variation of plasma conditions with the introduction of complex matrices. The levels and factors evaluated in this experiment and the experimental results are shown in Table S3.

All factors studied were considered significant $(\alpha=0.05)$. The influence of the factors was very similar for all elements. As expected, the ratio $\mathrm{Mg}^{\mathrm{II}} / \mathrm{Mg}^{\mathrm{I}}$ and the peristaltic pump speed were inversely proportional, that is, the higher the speed of the peristaltic pump, the lower the plasma robustness due to plasma loading by the sample solution. The plasma is considered robust if the ratio $\mathrm{Mg}^{\mathrm{II}} / \mathrm{Mg}^{\mathrm{I}}$ is $\geq 8$. Therefore, for any condition investigated the plasma was not considered robust. However, the value of this ratio can vary from one instrument to another and also depends on the type of nebulizer employed. Additional investigations focusing solely on the plasma robustness must be conducted, which was not in the scope of the present study.

The average probability for $\mathrm{S}$ (considered as representative of the three elements studied) and the ratio $\mathrm{Mg}^{\mathrm{II}} / \mathrm{Mg}^{\mathrm{I}}$ are shown in Figure 2 .

According to Figure 2, the plasma power affects the sensitivity and plasma robustness, being directly proportional to both. The pressure of the nebulizer gas is inversely proportional to the sensitivity and $\mathrm{Mg}^{\mathrm{II}} / \mathrm{Mg}^{\mathrm{I}}$ ratio that is in accordance with the literature. ${ }^{34,36-38}$ The speed of the peristaltic pump appears to be directly proportional to the sensitivity in Figure 2a but inversely proportional in Figure 2b. Figure 3 allows better visualization of the effects. The highest value of the plasma power $(1.45 \mathrm{~kW})$ for the range investigated was fixed to generate the surface responses shown in Figure 3.

Based on the results obtained and Figure 3, it was concluded that the best conditions for the plasma power and nebulizer gas pressure were $1.45 \mathrm{~kW}$ and $180 \mathrm{kPa}$, respectively. The speed of the peristaltic pump has little effect on the plasma robustness, but affects the sensitivity remarkably. Thus, the speed of the peristaltic pump was set at $24 \mathrm{rpm}\left(2.4 \mathrm{~mL} \mathrm{~min}^{-1}\right)$, the highest speed evaluated in the experimental planning (Table S3).

\section{Selectivity and matrix effects}

Two criteria were adopted for the spectral lines selection: (i) sensitivity and (ii) absence of spectral
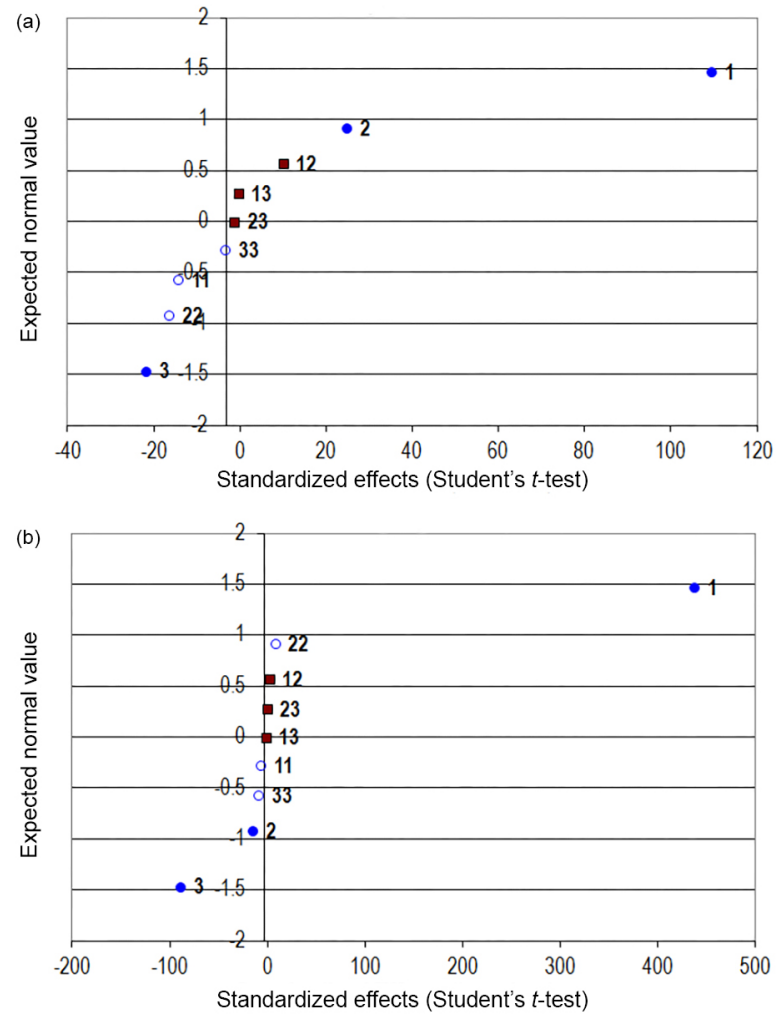

Figure 2. Average probability for (a) $\mathrm{S}$ and (b) $\mathrm{Mg}^{\mathrm{II}} / \mathrm{Mg}^{\mathrm{I}}$ ratio. The first factor is the plasma power, the second the peristaltic pump speed and the third the nebulizer gas pressure. The other effects shown are contributions of second order.

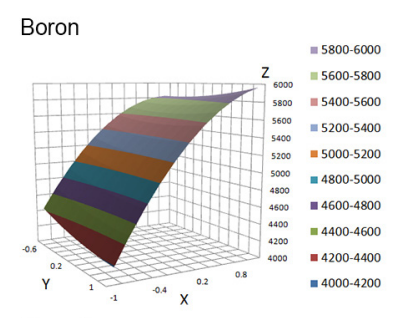

Phosphorus

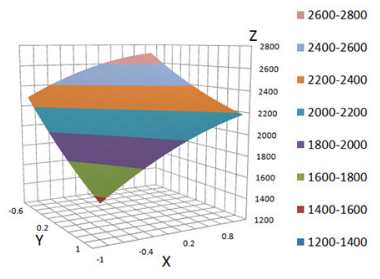

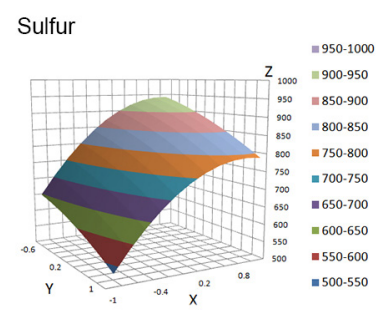

$\mathrm{Mg}(\mathrm{II}) / \mathrm{Mg}(\mathrm{I})$ ratio

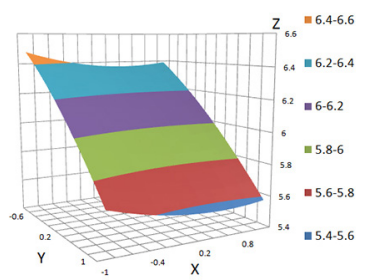

Figure 3. Response surface of the instrumental conditions; $X$ corresponds to the peristaltic pump speed (in matrix coordinates), $\mathrm{Y}$ the nebulizer gas pressure (in matrix coordinates) and $\mathrm{Z}$ the intensity of the analyte signal, except $\mathrm{Mg}^{\mathrm{II}} / \mathrm{Mg}^{\mathrm{I}}$ where $\mathrm{Z}$ corresponds to this ratio.

interference by major elements normally present in mineral fertilizer. However, these elements can cause non-spectral interference (matrix effect). It was considered that there is not a single matrix that represents all commercial fertilizers, but different formulations that can vary, depending on the desired composition of a given fertilizer. ${ }^{26}$ Therefore, 
potential interferences were evaluated for all types of mineral fertilizer. To this end, a multivariate analysis based on a Plackett-Burman planning was conducted (Table 3). ${ }^{39}$ This planning was used in view of the reduced number of experiments necessary. It should be pointed out that despite the better sensitivity of the Doehlert matrix approach, the number of experiments is higher than those necessary for the Plackett-Burman planning.

For evaluation of matrix effects, eight solutions containing $30 \mathrm{mg} \mathrm{L}^{-1}$ of $\mathrm{P}$ and $\mathrm{S}$, and $0.3 \mathrm{mg} \mathrm{L}^{-1}$ of $\mathrm{B}$ were prepared and spiked with potentially interfering substances (Table 3) and then analyzed. The analytes concentrations in these solutions corresponded to the central point of the calibration curves obtained. The $\mathrm{P}$ concentration was 10 to $20 \%$ lower than that in a two-fold diluted sample solution obtained according to the official method. ${ }^{6}$ The interference of NAC was also evaluated because this reagent is employed for P extraction according the official method. ${ }^{6}$

Three independent measurements were conducted in random order for each combination quoted in Table 3 and the respective median calculated. The mean concentrations of the analytes (in the absence or presence of interfering) are given in Table 4 where the positive sign indicates suppression of the analyte signal and the negative sign indicates that the interfering increased the analyte intensity.

The significance of the interference was estimated by equation 2:
$\Delta_{\text {crit }}>\frac{t_{\text {crit }} \mathrm{s}}{\sqrt{2}}$

where $\Delta_{\text {crit }}$ is the maximum variation considered as noncritical; $t_{\text {crit }}$ is the critical value for two tailed Student's $t$-test at a $95 \%$ confidence level (for $\mathrm{n}=8, t_{\text {crit }}$ is 2.36 ); and $\mathrm{s}$ is the standard deviation of the mean.

As can be seen in Table $4, \Delta_{\text {crit }}>t_{\text {crit }}$ for P $(213.618 \mathrm{~nm})$ and $\mathrm{P}(214.914 \mathrm{~nm})$. This was a consequence of spectral interference caused by $\mathrm{Cu}$. Thus, the spectral line $\mathrm{P}(213.547 \mathrm{~nm})$ was selected in experiments conducted thereafter. No interference was observed for S and B, except that of NAC. However, this interference would not affect the determination of $B$ and $S$ in fertilizer, since NAC is only used for P extraction. In this case, the interference can be corrected by preparing the calibration solutions in NAC. The experiment was further repeated without adding NAC ( $g=G$ in the Plackett-Burman matrix) and the results obtained demonstrated that there was not any significant matrix interference in the absence of NAC.

\section{Linearity}

In order to assess the linearity, calibration curves covering six different concentrations (not staggered) were obtained, whereas three solutions were prepared for each concentration, comprising eighteen independent solutions. Thus, 18 independent values were obtained for each

Table 3. Plackett-Burman planning to evaluate matrix effects. Capital letters indicate solutions without addition of interfering substance while lowercase letters indicate its addition. Interfering concentration: $\mathrm{K}_{2} \mathrm{O}=120 \mathrm{mg} \mathrm{L}^{-1} ; \mathrm{Ca}, \mathrm{Mg}, \mathrm{Cu}, \mathrm{Zn}$, and $\mathrm{Mn}=30 \mathrm{mg} \mathrm{L}^{-1}$; and NAC $=10 \%$ (m/v). The median values were rounded to contain the same number of decimal places as the standard deviations calculated (Table 4)

\begin{tabular}{|c|c|c|c|c|c|c|c|c|c|}
\hline \multirow{2}{*}{\multicolumn{2}{|c|}{$\begin{array}{l}\text { Possible interfering } \\
\text { substance }\end{array}$}} & \multicolumn{8}{|c|}{ Combination } \\
\hline & & 1 & 2 & 3 & 4 & 5 & 6 & 7 & 8 \\
\hline A or a & $\mathrm{K}_{2} \mathrm{O}^{\mathrm{a}}$ & A & A & A & A & $\mathrm{a}$ & $\mathrm{a}$ & $\mathrm{a}$ & A \\
\hline $\mathrm{B}$ or $\mathrm{b}$ & $\mathrm{Ca}$ & B & B & $\mathrm{b}$ & $\mathrm{b}$ & B & B & $\mathrm{b}$ & $\mathrm{b}$ \\
\hline $\mathrm{C}$ or $\mathrm{c}$ & $\mathrm{Mg}$ & $\mathrm{C}$ & $\mathrm{c}$ & $\mathrm{C}$ & $\mathrm{c}$ & $\mathrm{C}$ & $\mathrm{c}$ & $\mathrm{C}$ & $\mathrm{c}$ \\
\hline $\mathrm{D}$ or $\mathrm{d}$ & $\mathrm{Cu}$ & $\mathrm{D}$ & $\mathrm{D}$ & d & d & d & d & $\mathrm{D}$ & $\mathrm{D}$ \\
\hline E or e & $\mathrm{Zn}$ & $\mathrm{E}$ & $\mathrm{e}$ & $\mathrm{E}$ & $\mathrm{e}$ & $\mathrm{e}$ & $\mathrm{E}$ & $\mathrm{e}$ & E \\
\hline F or $f$ & $\mathrm{Mn}$ & $\mathrm{F}$ & $\mathrm{f}$ & $\mathrm{f}$ & $\mathrm{F}$ & $\mathrm{F}$ & $\mathrm{f}$ & $\mathrm{f}$ & $\mathrm{F}$ \\
\hline $\mathrm{G}$ or $\mathrm{g}$ & NAC & $\mathrm{G}$ & $\mathrm{g}$ & $\mathrm{g}$ & G & $\mathrm{g}$ & $\mathrm{G}$ & G & $\mathrm{g}$ \\
\hline \multirow{2}{*}{\multicolumn{2}{|c|}{ Analyte }} & \multicolumn{8}{|c|}{ Median concentration / $\left(\mathrm{mg} \mathrm{L}^{-1}\right)$} \\
\hline & & 1 & 2 & 3 & 4 & 5 & 6 & 7 & 8 \\
\hline \multicolumn{2}{|l|}{ B } & 0.3201 & 0.3015 & 0.3035 & 0.3567 & 0.3018 & 0.3407 & 0.3611 & 0.3005 \\
\hline \multicolumn{2}{|l|}{ S } & 32.53 & 29.45 & 29.41 & 32.10 & 29.77 & 32.05 & 32.22 & 29.36 \\
\hline \multicolumn{2}{|c|}{$\mathrm{P}(213.618 \mathrm{~nm})$} & 32.4 & 31.0 & 10.5 & 10.9 & 11.4 & 11.2 & 32.4 & 30.0 \\
\hline \multicolumn{2}{|c|}{$\mathrm{P}(214.914 \mathrm{~nm})$} & 32.5 & 31.0 & 14.8 & 17.2 & 15.5 & 17.1 & 32.6 & 30.2 \\
\hline \multicolumn{2}{|c|}{$\mathrm{P}(213.547 \mathrm{~nm})$} & 32.49 & 30.87 & 30.16 & 32.27 & 30.53 & 32.14 & 31.97 & 30.18 \\
\hline
\end{tabular}

${ }^{\mathrm{a}}$ As expressed in mineral fertilizer. NAC: neutral ammonium citrate. 
Table 4. Mean analyte concentration $(n=4)$ in the absence (capital letter) and presence (lowercase letter) of interfering substance. The standard deviation is that of the 8 median values given in Table 3

\begin{tabular}{|c|c|c|c|c|c|}
\hline \multirow{2}{*}{ Calculated parameter } & \multicolumn{5}{|c|}{ Concentration / $\left(\mathrm{mg} \mathrm{L}^{-1}\right)$} \\
\hline & $\mathrm{B}$ & S & $\mathrm{P}(213.618 \mathrm{~nm})$ & $\mathrm{P}(214.914 \mathrm{~nm})$ & $\mathrm{P}(213.547 \mathrm{~nm})$ \\
\hline A & 0.3204 & 30.87 & 21.2 & 23.9 & 31.45 \\
\hline a & 0.3260 & 30.85 & 21.3 & 23.8 & 31.21 \\
\hline B & 0.3160 & 30.95 & 21.5 & 24.0 & 31.51 \\
\hline $\mathrm{b}$ & 0.3305 & 30.77 & 21.0 & 23.7 & 31.14 \\
\hline $\mathrm{C}$ & 0.3216 & 30.99 & 21.7 & 23.8 & 31.29 \\
\hline $\mathrm{c}$ & 0.3248 & 30.74 & 20.8 & 23.9 & 31.37 \\
\hline $\mathrm{D}$ & 0.3208 & 30.89 & 31.5 & 31.5 & 31.38 \\
\hline d & 0.3257 & 30.83 & 11.0 & 16.2 & 31.27 \\
\hline $\mathrm{E}$ & 0.3162 & 30.84 & 21.0 & 23.6 & 31.24 \\
\hline $\mathrm{e}$ & 0.3303 & 30.89 & 21.4 & 24.1 & 31.41 \\
\hline $\mathrm{F}$ & 0.3198 & 30.94 & 21.2 & 23.9 & 31.37 \\
\hline $\mathrm{f}$ & 0.3267 & 30.78 & 21.3 & 23.8 & 31.28 \\
\hline G & 0.3446 & 32.23 & 21.7 & 24.8 & 32.22 \\
\hline $\mathrm{g}$ & 0.3018 & 29.50 & 20.7 & 22.9 & 30.43 \\
\hline Standard deviation & 0.0095 & 0.54 & 4.0 & 3.0 & 0.36 \\
\hline \multicolumn{6}{|c|}{ Difference among concentrations } \\
\hline$A-a$ & -0.0056 & 0.02 & -0.1 & 0.0 & 0.24 \\
\hline $\mathrm{B}-\mathrm{b}$ & -0.0145 & 0.18 & 0.5 & 0.3 & 0.36 \\
\hline $\mathrm{C}-\mathrm{c}$ & -0.0032 & 0.25 & 0.9 & 0.0 & -0.08 \\
\hline$D-d$ & -0.0049 & 0.06 & 20.4 & 15.4 & 0.10 \\
\hline $\mathrm{E}-\mathrm{e}$ & -0.0141 & -0.05 & -0.4 & -0.4 & -0.17 \\
\hline$F-f$ & -0.0070 & 0.16 & -0.1 & 0.0 & 0.08 \\
\hline $\mathrm{G}-\mathrm{g}$ & 0.0428 & 2.73 & 1.0 & 2.0 & 1.78 \\
\hline$\Delta_{\text {crit }}$ & 0.0159 & 0.90 & 6.7 & 5.1 & 0.61 \\
\hline
\end{tabular}

$\Delta_{\text {crit }}:$ maximum variation considered as non-critical.

analyte. The linear correlation coefficient of the calibration curves was 0.9985 for B and 0.9994 for S and P. The normality, homoscedasticity and absence of autocorrelation of residues were considered satisfactory. ${ }^{40}$ In addition, after exclusion of outliers following the jackknife test (1 for B and 4 for $\mathrm{S}$ and $\mathrm{P}$ ) any linearity deviation was not observed. ${ }^{30}$ It is important to remark that the jackknife model test allows deleting 4 from 18 values, but only 2 values for each concentration.

\section{Limits of detection and quantification}

The theoretical limits of detection (LODs) and quantification (LOQs) were estimated following the classic approach, ${ }^{2}$ i.e., from $n$ measurements of the analyte in the analytical blank. The extraction solutions subjected to the same treatment given to the sample were considered as blanks. Altogether, 21 independent determinations were carried out for each blank. The LODs and LOQs were calculated as follows: $\mathrm{LOD}=\mathrm{b}+3.3 \mathrm{~s} ; \mathrm{LOQ}=\mathrm{b}+10 \mathrm{~s}$, where $\mathrm{s}$ is the standard deviation of the 21 measurements and $b$ is the average of them. The value of $b$ was computed only when it was positive. The outliers were eliminated following the Grubbs test $(\alpha=0.05){ }^{40}$ To estimate the LODs and LOQs of the methods, $250 \mathrm{mg}$ of sample in $200 \mathrm{~mL}$ of solution were considered. For P extraction using $\mathrm{NAC}$, the sample mass and volume cited in the official method were considered ${ }^{6}$ (Supplementary Information). The calculated LODs and LOQs are given in Table 5, along with the minimum concentration of each nutrient in the fertilizer, that must be assured and informed by the supplier. ${ }^{26}$ As can be seen in Table 5, the theoretical LOQ is $\leq$ the minimum concentration that must be assured. Therefore, the LOQs meet the surveillance needs. There is not a minimum guarantee for $\mathrm{P}$, but only a recommendation for "NPK sum" (nitrogen + phosphorus + potassium 
concentrations) that must be at least $15 \%(\mathrm{~m} / \mathrm{m})$ in any mineral fertilizer. ${ }^{26}$

Table 5. Mean and standard deviation of 21 analyte measurements in the analytical blank, limits of detection (LODs) and quantification (LOQs) estimated for each analyte in fertilizer and minimum concentration that must be guaranteed by suppliers

\begin{tabular}{|c|c|c|c|}
\hline \multirow{2}{*}{ Parameter } & \multicolumn{3}{|c|}{ Analyte } \\
\hline & B & $\mathrm{S}$ & $\mathrm{P}$ \\
\hline Mean & -0.096 & 0.144 & 0.250 \\
\hline Standard deviation & 0.038 & 0.038 & 0.210 \\
\hline $\mathrm{LOD} /\left(\mathrm{mg} \mathrm{L}^{-1}\right)$ & 0.124 & 0.270 & 0.950 \\
\hline $\mathrm{LOQ} /\left(\mathrm{mg} \mathrm{L}^{-1}\right)$ & 0.378 & 0.525 & 2.36 \\
\hline $\mathrm{LOD} / \%$ & 0.010 & 0.022 & 0.048 \\
\hline LOQ / \% & 0.030 & 0.042 & 0.118 \\
\hline Minimum concentration / \% & $0.030^{\mathrm{a}}$ & $0.500^{\mathrm{a}}$ & $--^{\mathrm{b}}$ \\
\hline
\end{tabular}

${ }^{a}$ Expressed to contain the same number of decimal places as the limit of quantification (LOQ, in \%) for easier comparison; baccording to the Brazilian legislation there is no minimum concentration. LOD: limit of detection.

\section{Precision}

The intermediate precision was evaluated by analyzing five different samples covering a wide range of analyte concentration, whereas the measurements were carried out in different days. The mean, standard deviation and coefficient of variation of the results are informed in Table 6 . The limit value recommended by Horwitz was used as criteria for acceptance or rejection of the results; they were accepted if the variation coefficient was lower than the limit value. ${ }^{41,42}$ As can be seen in Table 6, the reproducibility was acceptable in all cases.

\section{Uncertainty estimation}

Figure 4 illustrates the cause and effect (i.e., fishbone) diagram ${ }^{43}$ for the standard uncertainty of the method, while the suggested mathematical model is given at the bottom of Figure 4.

As schematized in Figure 4, the analyte concentration measured (S) has three sources of uncertainty: ( $i$ ) deviations generated by an imperfect linear correlation $\left(\mathrm{R}^{2}\right.$ is not close to 1); (ii) inherited error and uncertainty from the standard; and (iii) standard dilution to obtain the calibration solutions. The dilution factor (DF) includes the contribution of uncertainties from the maximum acceptable errors for the volumetric flasks and pipettes and the liquid expansion at the temperature of the laboratory. Three factors contribute to the total error of the balance $(\mathrm{w})$ : measurement error and calibration uncertainty, eccentricity (incorrect position of
Table 6. Results obtained in the evaluation of intermediate precision. The mean values were rounded in order to have the same number of decimal places as the standard deviation

\begin{tabular}{lccccc}
\hline Analyte & Sample & $\begin{array}{c}\text { Mean } \\
(\mathrm{n}=6) / \\
\%(\mathrm{~m} / \mathrm{m})\end{array}$ & $\begin{array}{c}\text { Standard } \\
\text { deviation / } \\
(\mathrm{m} / \mathrm{m})\end{array}$ & $\begin{array}{c}\text { Variation } \\
\text { coefficient / } \\
\%\end{array}$ & $\begin{array}{c}\text { Horwitz } \\
\text { value / } \\
\%\end{array}$ \\
\hline \multirow{4}{*}{ B } & $1542 \mathrm{~F} / 14$ & 0.0709 & 0.0019 & 2.663 & 5.958 \\
& $1606 \mathrm{~F} / 14$ & 10.64 & 0.10 & 0.97 & 2.80 \\
& $1731 \mathrm{~F} / 14$ & 0.0418 & 0.0011 & 2.730 & 6.451 \\
& $\mathrm{~F} 118 / 13$ & 1.049 & 0.042 & 3.957 & 3.971 \\
& $1364 \mathrm{~F} / 14$ & 0.2393 & 0.0054 & 2.260 & 4.961 \\
\hline & $0162 \mathrm{~F} / 15$ & 13.59 & 0.32 & 2.34 & 2.70 \\
$\mathrm{~S}$ & $1605 \mathrm{~F} / 14$ & 10.97 & 0.10 & 0.89 & 2.79 \\
& $0205 \mathrm{~F} / 15$ & 2.114 & 0.038 & 1.800 & 3.574 \\
& $\mathrm{~F} 0289 / 13$ & 7.01 & 0.10 & 1.44 & 2.98 \\
& $1722 \mathrm{~F} / 14$ & 5.889 & 0.083 & 1.417 & 3.063 \\
\hline & $0162 \mathrm{~F} / 15$ & 11.05 & 0.22 & 2.03 & 2.79 \\
& $0172 \mathrm{~F} / 15$ & 13.61 & 0.16 & 1.15 & 2.70 \\
$\mathrm{P}$ & $1197 \mathrm{~F} / 14$ & 5.54 & 0.10 & 1.84 & 3.09 \\
& $0186 \mathrm{~F} / 15$ & 7.35 & 0.17 & 2.26 & 2.96 \\
& $0213 \mathrm{~F} / 15$ & 6.60 & 0.09 & 1.36 & 3.01 \\
\hline
\end{tabular}

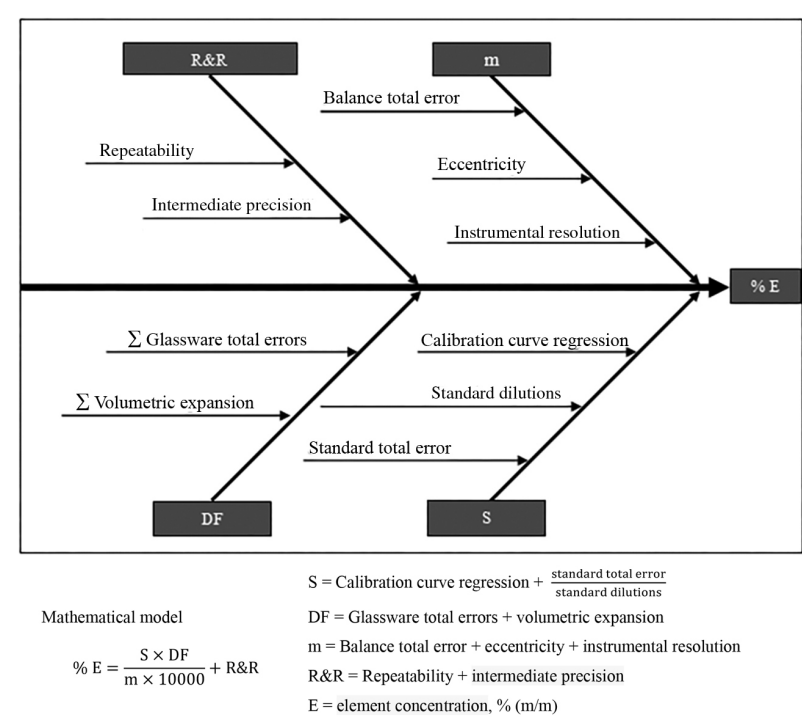

Figure 4. Causes and effects diagram and mathematical model suggested for the random effects in the determination of $\mathrm{B}, \mathrm{S}$ and $\mathrm{P}$ in mineral fertilizer.

the sample on the plate of the balance) and the resolution of the balance.

The intermediate precision was estimated by measuring the analyte in a significant number of sample replicates and varying certain conditions. In the present study the day of analysis and sample composition were varied. The measurements were conducted by the same analyst using the same ICP OES instrument. 
The contribution of the analytical curve $\left(\mathrm{L}_{1}\right)$ to the uncertainty was estimated according to GUM using a linear regression equation for calculating the uncertainty generated by deviations..$^{31}$ The input values for the equation were those from the calibration curves generated to determine the intermediate precision.

The uncertainty originating from the standard $\left(\mathrm{L}_{2}\right)$ was calculated by the difference among the nominal (1000 $\mathrm{mg} \mathrm{L}^{-1}$ ) and the actual concentration (that informed on the certificate of the standard). For simplicity, this value (B: $4 \mathrm{mg} \mathrm{L}^{-1}$, P: $5 \mathrm{mg} \mathrm{L}^{-1}$, and S: $9 \mathrm{mg} \mathrm{L}^{-1}$ ) was considered the maximum accepted by the laboratory, showing a quadratic distribution. Thus, the uncertainty contribution of this factor was obtained by dividing the error by the square root of 3 .

The contribution of uncertainty due to the dilution of the standards $\left(\mathrm{L}_{3}\right)$ was obtained by the sum of the acceptable errors for pipettes and volumetric flasks (Table S1) and the liquid expansion.

The contribution of the sample dilution uncertainty (FD) was estimated by summing the errors tolerated for the volumetric devices (Table S1) to the water volumetric expansion (FD2) and dividing the sum by the square root of 3. The expansion coefficient of water $\left(2.1 \times 10^{-4}{ }^{\circ} \mathrm{C}^{-1}\right)$ at the temperature of the laboratory $\left(15\right.$ to $\left.25^{\circ} \mathrm{C}\right)$ was considered as FD2. ${ }^{44}$

The uncertainty of the sample mass was calculated by considering the balance error, eccentricity, and balance resolution. The acceptable error for the balance $\left(\mathrm{m}_{1}\right)$ was $0.3 \mathrm{mg}$, while the balance resolution $\left(\mathrm{m}_{2}\right)$ was $0.1 \mathrm{mg}$. Half of the resolution $(0.05 \mathrm{mg})$ was considered in the calculation because the error is caused by an instrumental automatic rounding that is up to half of the resolution of the balance. It was assumed that the distribution of the errors due to $m_{1}$ and $m_{2}$ is rectangular. Thus, the uncertainty of $\mathrm{m}_{1}$ and $\mathrm{m}_{2}$ was estimated by dividing the respective errors by the square root of 3 .

The eccentricity $\left(\mathrm{m}_{3}\right)$ was determined empirically in the laboratory by placing the sample on 5 different points on the weighing plate of the balance (one on the middle and four on equidistant points). In this way, the eccentricity was estimated as $0.0002 \mathrm{~g}$. The statistical distribution of such measurements is triangular. So, the estimated value was divided by the square root of 6 .

In order to calculate the contribution of the intermediate precision $(R \& R)$ for the uncertainty, the individual values of the concentrations found in the study of precision (Table S6) were normalized to the expected concentrations. The outliers were excluded according to the Grubbs test ${ }^{40}$ and then the contribution of the intermediate precision $^{41}$ was estimated through equation 3.
$S_{R \& R}=\sqrt{\frac{1}{t(n-1)} \sum_{j=1}^{t} \sum_{k=1}^{n}\left(y_{j k}-\bar{y}_{j}\right)^{2}}$

where $S_{\text {R\&R }}$ is the standard deviation; $t$ is the number of samples; $\mathrm{n}$ is the number of measurements per sample; $\mathrm{j}$ is the sample; $k$ is the number of analysis of sample $j ; y_{j k}$ is the value of the result $\mathrm{k}$ for sample $\mathrm{j}$; and is the arithmetic mean of the results for sample $j$.

To estimate the contribution of the individual samples for the R\&R uncertainty, the standard deviation obtained in equation 3 was multiplied by the concentration of the analyte measured in each determination.

The contribution of the accuracy to the uncertainty of the method was estimated by considering the analyte recovery in samples where the analyte concentration was already known. The results were normalized and the mean compared to the expected value, following Student's $t$-test (two-tailed distribution, 95\% of confidence level) ${ }^{40}$ If $t_{\text {calculated }}<t_{\text {crit }}$ the mean was not significantly different than the expected value (recovery of $100 \%$ ). In this case, the contribution of the accuracy could be neglected, and the difference among the concentration found and the actual concentration was merely a random variation already computed in the precision. If $t_{\text {calculated }}>t_{\text {crit }}$, the accuracy was considered as a contributing factor for the uncertainty. The calculated $t$ values $(\mathrm{n}=30)$ were 2.609 for $\mathrm{B}, 1.563$ for $\mathrm{S}$ and 10.434 for $\mathrm{P}$, whereas $t_{\text {crit }}$ was 2.045 . Thus, for $\mathrm{B}$ and $\mathrm{P}$, the accuracy was considered a contributing factor for the combined standard uncertainty.

The contributions of each component and the sensitivity coefficients calculated for each relevant component in estimating the uncertainty are given in Tables S4 and S5. The combined and expanded uncertainties are given in Table 7, which were obtained from the data used to calculate the contribution of each component and the sensitivity coefficients (Tables S4 and S5) ${ }^{45}$ The relative contribution of each component is informed in Table 8. The percentage of contribution of the random and systemic effects was calculated and then the contribution of the random effect (cited in Table 7) was multiplied by the relative uncertainty of the random effects. In this way, the sum of the total effect was $100 \%$, relativizing the contribution of each component.

According to Table 7, the total relative standard uncertainty ranges from 4.3 to $7.8 \%$, depending on the analyte. It is worth citing that the uncertainty may vary, which depends on the analyte concentration in the fertilizer sample. For example, the intermediate precision tends to contribute more to the uncertainty when the analyte concentration is low while the dilution factor does when the analyte concentration is high. As can be seen in Table 8, the major 
Table 7. Expanded and combined uncertainties of the methods of B, P and S determination in mineral fertilizer by ICP OES

\begin{tabular}{|c|c|c|c|c|}
\hline \multicolumn{2}{|l|}{ Uncertainty components } & $\mathrm{B}$ & $\mathrm{S}$ & $\mathrm{P}$ \\
\hline \multicolumn{2}{|c|}{ Analyte concentration in the sample $/ \%(\mathrm{~m} / \mathrm{m})$} & 0.232 & 5.87 & 7.11 \\
\hline \multirow[t]{3}{*}{ Analyte concentration (S) } & $\mathrm{L}_{1}$ (calibration curve regression) & 0.0030 & 0.0532 & 0.1513 \\
\hline & $\mathrm{L}_{2}$ (total error of standards) & 0.0000 & 0.0024 & 0.0017 \\
\hline & $\mathrm{L}_{3}$ (dilutions) & -0.0018 & -0.0480 & -0.0578 \\
\hline Dilution factor (DF) & DF (maximum error tolerated) & 0.0019 & 0.0186 & 0.1231 \\
\hline \multirow[t]{3}{*}{ Sample mass (m) } & $\mathrm{m}_{1}$ (balance total error) & 0.0000 & -0.0041 & -0.0012 \\
\hline & $\mathrm{m}_{2}$ (balance resolution) & 0.0000 & -0.0007 & -0.0002 \\
\hline & $\mathrm{m}_{3}($ eccentricity $)$ & 0.0000 & -0.0019 & -0.0006 \\
\hline \multicolumn{2}{|l|}{$R \& R$ (intermediate precision) } & 0.0065 & 0.0983 & 0.1308 \\
\hline \multicolumn{2}{|l|}{ Combined uncertainty } & 0.0076 & 0.1232 & 0.2418 \\
\hline \multicolumn{2}{|l|}{ Effective degree of freedom } & 44 & 55 & 76 \\
\hline \multicolumn{2}{|l|}{ Coverage factor $(\mathrm{k})^{\mathrm{a}}$} & 2.06 & 2.05 & 2.03 \\
\hline \multicolumn{2}{|c|}{ Expanded uncertainty $/ \%(\mathrm{~m} / \mathrm{m})$} & 0.016 & 0.25 & 0.49 \\
\hline \multicolumn{2}{|c|}{ Relative standard uncertainty of random components / \% } & 6.7 & 4.3 & 6.9 \\
\hline \multicolumn{2}{|c|}{ Relative standard uncertainty of accuracy / \% } & 2.4 & 0.0 & 3.6 \\
\hline \multicolumn{2}{|c|}{ Total relative standard uncertainty / \% } & $7.1^{\mathrm{b}}$ & $4.3^{\mathrm{b}}$ & $7.8^{\mathrm{b}}$ \\
\hline
\end{tabular}

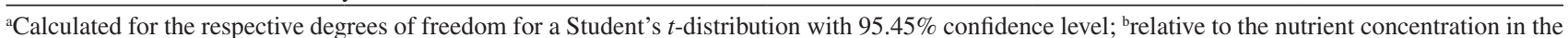
sample.

Table 8. Relative contribution of the components to the uncertainty in the determination of $\mathrm{B}, \mathrm{S}$ and $\mathrm{P}$ in mineral fertilizer by ICP OES

\begin{tabular}{|c|c|c|c|c|}
\hline Uncertainty components & & $\mathrm{B}$ & $\mathrm{S}$ & $\mathrm{P}$ \\
\hline \multirow[t]{3}{*}{ Analyte concentration $(\mathrm{S})$} & $\mathrm{L}_{1}$ (calibration curve regression) / \% & 14 & 19 & 31 \\
\hline & $\mathrm{L}_{2}$ (standard error) $/ \%$ & 0 & 0 & 0 \\
\hline & $\mathrm{L}_{3}$ (standard dilutions) / \% & 5 & 15 & 5 \\
\hline Dilution factor (DF) & $\mathrm{DF}$ (maximum tolerated error) / \% & 5 & 2 & 20 \\
\hline \multirow[t]{3}{*}{ Sample mass weighing $(\mathrm{m})$} & $\mathrm{m}_{1}$ (balance total error) $/ \%$ & 0 & 0 & 0 \\
\hline & $\mathrm{m}_{2}$ (balance resolution) $/ \%$ & 0 & 0 & 0 \\
\hline & $\mathrm{m}_{3}$ (eccentricity) /\% & 0 & 0 & 0 \\
\hline Intermediate precision / \% & & 65 & 64 & 23 \\
\hline Accuracy / \% & & 11 & 0 & 21 \\
\hline
\end{tabular}

factors of uncertainty are the calibration curve regression, standard solution dilution, dilution factor of sample solution, intermediate precision (R\&R), and accuracy. However, the uncertainty values are still an indicative for improving the quality of the methods instead of rigid and definitive values. ${ }^{46}$ Additionally, the contributions of the intermediate precision and accuracy to the uncertainty may have been overestimated. They may be decreased after the implementation of the methods in the routine of the laboratory where the use of a control chart is recommended. The history of the accuracy will not only allow monitoring of the laboratory conditions, but also demonstrates the evolution of the parameters over time - this is not possible with a limited number of samples as is the case of the present study.

\section{Samples analysis}

Certified reference materials and an inter-laboratory program sample were analyzed - the certified reference materials were analyzed in triplicate and the inter-laboratory sample in duplicate. The medians of the concentrations found for the replicates were compared with the certified or informed values. The reference materials were decomposed in microwave oven, according to the method optimized in the present study. For P determination in the inter-laboratory program sample, the official method was followed for better comparison of the results. ${ }^{6}$ For S and B determination, this sample was decomposed in microwave oven.

The reports of the inter-laboratory program did not inform the measurement uncertainties due to the low number of participants. Instead of informing the uncertainty, the z-score calculated for the inter-quartile range is given. ${ }^{27} \mathrm{~A}$ value of $\mathrm{z}$-score lower than 2 , in absolute value, means that the results found are satisfactory; between 2 and 3 they are "questionable"; and higher than 3 they are "unsatisfactory". The concentrations found for the duplicate were used to obtain the standardized sum (sp) and the z-score. ${ }^{27}$ It can be seen in Table 9 that the results obtained were satisfactory since the analyte recovery was statistically not different from $100 \%$ and the normalized 
Table 9. Analyte concentration found in the analysis of certified reference materials and sample from inter-laboratory program

\begin{tabular}{|c|c|c|c|c|c|c|c|c|}
\hline Sample & Analyte & $\begin{array}{l}\text { Found / \% } \\
(\mathrm{m} / \mathrm{m})\end{array}$ & $\begin{array}{c}\text { Certified / \% } \\
(\mathrm{m} / \mathrm{m})\end{array}$ & $\mathrm{sp}^{\mathrm{a}}$ & $\mathrm{M}^{\mathrm{a}}$ & $\mathrm{IQN}^{\mathrm{a}}$ & $\begin{array}{c}\text { Normalized } \\
\text { error or Z-score }\end{array}$ & Recovery / \% \\
\hline NIST 694 & $P$ & $13.5 \pm 1.1^{c}$ & $13.18 \pm 0.04$ & - & - & - & 0.29 & 102 \\
\hline \multirow[t]{2}{*}{ NIST 695} & $\mathrm{P}$ & $7.37 \pm 0.75^{\mathrm{c}}$ & $7.2 \pm 0.1$ & - & - & - & 0.22 & 102 \\
\hline & B & $0.11 \pm 0.01^{\mathrm{c}}$ & $0.111 \pm 0.002$ & - & - & - & 0.10 & 100 \\
\hline \multirow[t]{3}{*}{$001 / 2015$} & B & $\begin{array}{l}0.186 \\
0.191\end{array}$ & - & 0.266 & 0.276 & 0.276 & -0.53 & - \\
\hline & S & $\begin{array}{l}2.17 \\
2.07\end{array}$ & - & 2.997 & 2.857 & 2.857 & 1.97 & - \\
\hline & $\mathrm{P}$ & $\begin{array}{l}10.35 \\
10.36\end{array}$ & - & 14.64 & 14.30 & 14.30 & 1.34 & - \\
\hline
\end{tabular}

astimated values of the standardized sum (sp), median $(\mathrm{M})$ and normalized interquartile range (IQN) for the participants of the inter-laboratory program; bnormalized error refers to NIST 694 and NIST 695 and z-score refers to sample 001/2015; cexpanded uncertainty.

error (Supplementary Information) and z-score were lower than 1 and 2, respectively. ${ }^{47}$

To assess the accuracy of the method developed for $\mathrm{S}$ determination in the commercial formulation, $100 \mathrm{mg}$ of elemental sulfur were added to $150 \mathrm{mg}$ of sample, which was carried out in triplicate. The sample decomposition was assisted by microwave radiation. The median of the recovery values and uncertainty were $102.3 \pm 4.3 \%$ $(\mathrm{k}=2.05)$, considered satisfactory.

\section{Conclusions}

For total P, S (as sulfate) and B determination in mineral fertilizers, the analytes extraction can be conducted in an open flask and heating for two min on hot plate. However, if $\mathrm{S}$ is present in its elemental form, the fertilizer sample should be decomposed in closed flask assisted by microwave radiation for accurate $\mathrm{S}$ quantification. The conditions considered optimal for plasma power, nebulizer gas pressure and the peristaltic pump speed in $\mathrm{P}, \mathrm{S}$ and $\mathrm{B}$ determination using ICP OES were $1.45 \mathrm{~kW}, 180 \mathrm{kPa}$ and $24 \mathrm{rpm}\left(2.4 \mathrm{~mL} \mathrm{~min}^{-1}\right)$, respectively.

The extraction solution NAC gives rise to significant matrix effect for all analytes. Therefore, when NAC is present in the sample solution, the calibration solutions should be prepared in the presence of this extractor. Copper interferes spectrally in P (213.618 and $214.914 \mathrm{~nm}$ ) but does not interfere in $\mathrm{P}(213.547 \mathrm{~nm})$. Potassium, $\mathrm{Ca}, \mathrm{Mg}$, $\mathrm{Zn}$, and $\mathrm{Mn}$ do not interfere in the determination of $\mathrm{B}$ and $\mathrm{S}$ at the conditions of the developed methods.

The measurement uncertainties, estimated by the bottom-up approach, ${ }^{31}$ were $7.1,4.3$, and $7.8 \%$ for $\mathrm{B}, \mathrm{S}$, and $\mathrm{P}$, respectively. The main uncertainty factors identified were the intermediate precision, accuracy, calibration curve regression and the inherited uncertainty of the measured volume/released by the volumetric devices used (glassware and micropipettes).

\section{Supplementary Information}

Supplementary information (procedures transcribed from official methods, Figure and Tables, and formula to calculate the normalized error) is available free of charge at http://jbcs.sbq.org.br as PDF file.

\section{Acknowledgments}

The authors are grateful to Ministério da Agricultura, Pecuária e Abastecimento (MAPA) for financial support and Conselho Nacional de Desenvolvimento Científico e Tecnológico (CNPq) for scholarships.

\section{References}

1. Ministério do Desenvolvimento, Indústria e Comércio Exterior (MDIC), Balança Comercial Brasileira: Dados Consolidados 2014, MDIC: Brasília, 2015.

2. http://anda.org.br/index.php?mpg=03.00.00\&ver=por accessed in March 2016.

3. Food and Agriculture Organization (FAO); World Fertilizer Trends and Outlook to 2018; FAO: Rome, 2015.

4. Heffer, P.; Prud'homme, M. Fertilizer Outlook 2014-2018. IFA: Sydney, 2014; http://www.fertilizer.org/en/ItemDetail?iProduc tCode=9787Pdf $\&$ Category=ECO accessed in March 2016.

5. Brasil; Decreto No. 4.954, de 14 de Janeiro de 2004; http:// www.planalto.gov.br/ccivil_03/_ato2004-2006/2004/decreto/ d4954.htm accessed in March 2016.

6. Ministério da Agricultura, Pecuária e Abastecimento (MAPA); Manual de Métodos Analíticos Oficiais para Fertilizantes Minerais, Orgânicos, Organominerais e Corretivos; MAPA: Brasília, 2014.

7. Food and Agriculture Organization (FAO); FAO Fertilizer and Plant Nutrition Bulletin 19: Guide to Laboratory Establishment for Plant Nutrient Analysis; FAO: Rome, 2008.

8. European Parliament; Regulation (EC) No. 2003/2003 of the 
European Parliament and of the Council of 13 October 2003 Relating to Fertilisers; EU: Luxembourg, 2003.

9. AOAC International Official Method 982.01: Boron (Acid- and Water-Soluble) in Fertilizers: Spectrophotometric Method; AOAC: Rockville, 2006.

10. AOAC International Official Method 980.02: Sulfur in Fertilizers: Gravimetric Method; AOAC: Rockville, 1985.

11. AOAC International Official Method 962.02: Phosphorus (Total) in Fertilizers: Gravimetric Quinolinum Molybdophosphate Method; AOAC: Rockville, 1965.

12. ABNT. ABNT Catálogo; www.abntcatalogo.com.br accessed in March 2016.

13. AOAC International, Official Method 2006.03: Arsenic, Cadmium, Cobalt, Chromium, Lead, Molybdenum, Nickel, and Selenium in Fertilizers, AOAC: Rockville, 2009.

14. Matilainen, R; Tummavuori, J.; J. AOAC Int. 1995, 3, 598.

15. Yang, W. M.; Boles, R. L.; Mawhinney, T. P.; J. AOAC Int. 2002, 6, 1241.

16. Matilainen, R.; Tummavuori, J.; J. AOAC Int. 1996, 5, 1026.

17. Bartos, J. M.; Boggs, B. L.; Falls, J. H.; Siegel, S. A.; J. AOAC Int. 2014, 3, 687.

18. Wu, P.; Wu, X.; Hou, X.; Young, C. G.; Jones, B. T.; Appl. Spectrosc. Rev. 2009, 44, 507.

19. Souza, S. O.; Costa, S. S. L.; Santos, D. M.; Pinto, J. S.; Garcia, C. A. B.; Alves, J. P. H.; Araújo, R. G. O.; Spectrochim. Acta, Part B 2014, 96, 1.

20. Ferreira, S. L. C.; Santos, W. N. L.; Quintella, C. M.; Neto, B. B.; Bosque-Sendra, J. M.; Talanta 2004, 63, 1061.

21. Ebrahimi-Najafabadi, H.; Leardi, R.; Jalali-Heravi, M.; J. AOAC Int. 2014, $1,12$.

22. Santos, D. C. M. B.; Carvalho, L. S. B.; Lima, D. C.; Leão, D. J.; Teixeira, L. S. G.; Korn, M. G. A.; J. Food Compos. Anal. 2014, 34, 75.

23. Ferreira, S. L. C.; Korn, M. G. A.; Ferreira, H. S.; Silva, E. G. P.; Araújo, R. G. O.; Souza, A. S.; Macedo, S. M.; Lima, D. C.; Jesus, R. M.; Amorim, F. A. C.; Bosque-Sendra, J. M. B.; Appl. Spectrosc. Rev. 2007, 5, 471.

24. Depoi, F. S.; Bentlin, F. R. S.; Ferrão, M. F.; Pozebon, D.; Anal. Methods 2012, 4, 2809.

25. Costa, S. S. L.; Pereira, A. C. L.; Passos, E. A.; Alves, J. P. H.; Garcia, C. A. B.; Araujo, R. G. O.; Talanta 2013, 108, 157.

26. Ministério da Agricultura, Pecuária e Abastecimento (MAPA); Instrução Normativa No. 5, de 23 de fevereiro de 2007; http:// sistemasweb.agricultura.gov.br/sislegis/action/detalhaAto. do?method=recuperarTextoAtoTematicaPortal\&codigo Tematica=1229260 accessed in March 2016.

27. Ministério da Agricultura, Pecuária e Abastecimento (MAPA); Programa de Ensaios de Proficiência em Análises de Fertilizantes e Corretivos do Mapa. Relatório da $1^{a}$ Rodada de 2015; MAPA: Brasília, 2015.

28. Teófilo, R. F.; Ferreira, M. M.; Quim. Nova 2006, 2, 338.
29. Laboratório de Quimiometria Teórica e Aplicada, Instituto de Química, Universidade Estadual de Campinas. Planilhas Eletrônicas para Cálculos de Planejamentos Experimentais; http://lqta.iqm.unicamp.br/portugues/Downloads.html\#teofilo accessed in March 2016

30. Souza, S. V. C.; Junqueira, R. G.; Anal. Chim. Acta 2005, 552, 25.

31. Joint Committee for Guides in Metrology (JCGM); Evaluation of Measurement Data - Guide to the Expression of Uncertainty in Measurement, JCGM 100:2008, JCGM: Sèvres, 2008.

32. Cataldi, T. R. I.; Orlando, D.; Nardiello, D.; Rubino, A.; Bianco, G.; Abate, S.; Ciriello, R.; Guerrieri, A.; Anal. Chim. Acta 2007, 597, 129.

33. Giné, M. F.; Espectrometria de Emissão Atômica; CPG-CENAUSP: Piracicaba, 1998.

34. Guimarães-Silva, A. K.; de Lena, J. C.; Fores, R. E. S.; Costa, L. M.; Nascentes, C. C.; J. Braz. Chem. Soc. 2012, 23, 753.

35. Mermet, J. M.; J. Anal. At. Spectrom. 1998, 13, 419.

36. Mermet, J. M.; Anal. Chim. Acta 1991, $250,85$.

37. Grotti, M.; Magi, E.; Frache, R.; J. Anal. At. Spectrom. 2000 , $15,89$.

38. Novotny, I.; Farias, J. C.; Jia-Liang, W.; Poussel, E.; Mermet, J. M.; Spectrochim. Acta, Part B 1996, 51, 1517.

39. Neto, B. B.; Scarminio, I. S.; Bruns, R. E.; Como Fazer Experimentos; Bookman: Porto Alegre, 2010.

40. Miller, J. N.; Miller, J. C.; Statistics and Chemometrics for Analytical Chemistry; Dorset Press: Dorchester, 2000.

41. Instituto Nacional de Metrologia, Qualidade e Tecnologia (Inmetro); Orientação sobre Validação de Métodos Analíticos, DOQ-CGCRE-008; Inmetro: Rio de Janeiro, 2010.

42. Ministério da Agricultura, Pecuária e Abastecimento (MAPA), Coordenação-Geral de Apoio Laboratorial (CGAL)/Divisão de Ensaios Químicos (DEQ); Manual de Validação, Verificação/ Confirmação de Desempenho, Estimativa da Incerteza de Medição e Controle de Qualidade Intralaboratorial; MAPA: Brasília, 2014.

43. Eurachem/Cooperation on International Traceability in Analytical Chemistry (CITAC) Guide CG 4: Quantifying Uncertainty in Analytical Measurement, $3^{\text {rd }}$ ed., 2012; http:// www.citac.cc/QUAM2012_P1.pdf accessed in March 2016.

44. Rede Metrológica RS; Incerteza de Medição: Guia Prático do Avaliador de Laboratórios, RM 68, Rev. 05; Rede Metrológica: Porto Alegre, 2013.

45. Chuí, Q. S. H.; J. Braz. Chem. Soc. 2007, 18, 424.

46. Thompson, M.; Analyst 1995, 120, 117N.

47. ISO Guide 13528: Statistical Methods for Use in Proficiency Testing by Interlaboratory Comparisons, ISO: Geneva, 2005.

Submitted: December 29, 2015

Published online: March 23, 2016

FAPERGS/CAPES has sponsored the publication of this article. 